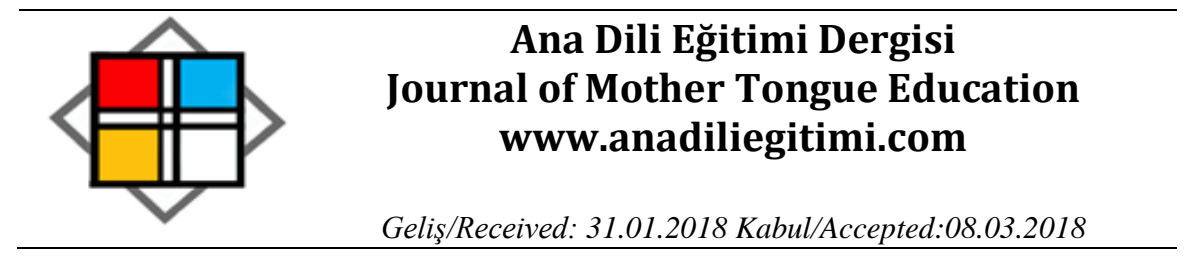

\title{
Yaratıcı Drama Yönteminin İlkokul 4. Sınıf Öğrencilerinin Okuma Motivasyonu ve Tutumlarına Etkisi *
}

\author{
Tolga ERDOĞAN** \\ Özge ERDOĞAN*** \\ Fatma Gül UZUNER ${ }^{* * * *}$
}

\begin{abstract}
Öz
Bu araştırmanın amacı, yaratıcı drama yönteminin ilkokul 4. sınıf öğrencilerinin okuma motivasyonu ve tutumlarına etkisini belirlemektir. Araştırma, Trabzon ilindeki bir belde okulunda ilkokul 4. sınıfta okuyan 16 öğrenciyle gerçekleştirilmiştir. Araştırmada, Türkçe dersinde yaratııı drama yöntemiyle toplam 30 ders saati okuma çalışmaları yapılmışıı. Araştırmada "tek grup ön test-son test deneysel desen" kullanılmıştır. Araştırmada elde edilen verilerin toplanması, analizi ve yorumlanmasında nicel araştırma yöntemi kullanılmıştır. Bu kapsamda öğrencilerin okumaya ilişkin motivasyon ve tutumlarını belirlemek için "Okuma Motivasyonu Profili Ölçeği" (Yıldız, 2013) ve "Okumaya Yönelik Tutum Ölçeği" (Susar Kırmızı, 2008) kullanılmıştır. Illgili ölçekler uygulamaların başında ön test, sonunda ise son test olarak uygulanmıştır. Verilerin analizinde "Wilcoxon Iş̧aretli Sıralar Testi" kullanılmıştır. Araştırma sonucunda, yaratıcı drama yönteminin öğrencilerin okuma motivasyonlarını olumlu yönde etkilediği, okumaya ilişkin tutumlarını ise etkilemediği sonucuna ulaşılmışır. Araştırmada elde edilen sonuçlar ışığında ilkokuldaki okuma öğretimi sürecine yönelik öneriler getirilmiştir.
\end{abstract}

Anahtar Kelimeler: Yaratıcı drama, okuma, okuma motivasyonu, okuma tutumu, ilkokul

\section{The Effect of the Creative Drama Method on the Reading Motivation and Attitudes of the $4^{\text {th }}$ Grade Students}

\begin{abstract}
The aim of the research is to determine the effect of the creative drama method on the reading motivation and attitudes of the 4th grade students. The research was carried out with $164^{\text {th }}$ grade students. In the research, using the creative drama method, a total of 30 class hours of reading practice was given in the Turkish course. In the study, the "single group pre-test post-test experimental design" was used. Quantitative research techniques were used in the collection, analysis, and interpretation of the data. For data collection, the "Reading Motivation Profile Scale" (Yıldız, 2013) and the "Reading Attitude Scale" (Susar Kırmızı, 2008) were used to
\end{abstract}

\footnotetext{
* Bu çalışma, XV. Uluslararası Sınıf Öğretmenliği Eğitimi Sempozyumu’nda sözlü bildiri olarak sunulmuştur.

** Doç. Dr., Karadeniz Teknik Üniversitesi, Fatih Eğitim Fakültesi, Temel Eğitim Bölümü, Trabzon, tolgaerdogan.edu@gmail.com

*** Dr. Öğr. Üyesi, Karadeniz Teknik Üniversitesi, Fatih Eğitim Fakültesi, Temel Eğitim Bölümü, Trabzon, erdoganozge.edu.edu@gmail.com

${ }^{* * * *}$ Arş. Gör., Kafkas Üniversitesi, Eğitim Fakültesi, Temel Eğitim Bölümü, Kars, fgu61@hotmail.com
} 
determine the motivation and attitudes of the students towards reading. The scales were used as the pre-test at the beginning of the research and as the post-test at the end. For data analysis, the Wilcoxon Signed Rank Test was used. The results showed that the creative drama method affected the reading motivation of the students positively, but it did not affect their attitudes towards reading. In the light of the results obtained in the research, suggestions were made for the improvement of the process of reading instruction in elementary school.

Keywords: Creative drama, reading, motivation for reading, attitude toward reading, elementary school

\section{Giriş}

Okuryazarlık becerilerinin temelinde okuma yer almaktadır. Okuma, insanların yaşamlarında ve gelişimlerinde oldukça önemli bir beceridir. İnsanlar, yaşamları boyunca pek çok bilgiyi okuyarak öğrenirler. Razon'a göre (1982) okuma, yazılı veya basılı işaretleri, belli kurala uyarak seslendirmektir. Harris ve Sipay (1990) okumayı, yazılı dili anlamlı bir şekilde yorumlamak şeklinde tanımlamıştır. Akyol’a (2012) göre ise okuma, ön bilgilerin kullanıldığı, yazar ve okuyucu arasındaki etkili iletişime dayalı, uygun bir yöntem ve amaç doğrultusunda, düzenli bir ortamda gerçekleştirilen anlam kurma sürecidir.

Okuma, birçok dilsel ve bilişsel becerinin gelişimine katkıda bulunan bir beceridir (Sylva ve Hurry, 1996). Yazılı metinden anlam çıkarma amacıyla okuyucu tarafından gerçekleştirilmesi ve düzenlenmesi gereken karmaşık bir çabadır. Okuyucu, hızlı ve doğru bir şekilde kelimeleri tanımalı ve okuduğu metinden çıkarım yapmalıdır (Denton ve Al Otaiba, 2011). Okuma, kelime tanımayı, kelimenin şifresini çözmeyi, sözcük dağarcığı, metnin ana fikrini bulma ve özetleme gibi bazı temel becerileri edinmeyi gerektirir. Tüm bu beceriler de düşünme sürecini içine alır. Okuma aynı zamanda bir düşünme eylemidir (Burns, Roe ve Ross, 1992; Çelenk, 2007; Hollingsead ve Ostrander, 2006; Small ve Arnone, 2011).

Okumayla ilgili yapılan tanımlar ve açıklamalar incelendiğinde okumanın daha çok bilişsel yönü üzerinde durulduğu görülmektedir. Oysaki okuma, bilişsel, sosyal, psikolojik ve duyuşsal yönleri olan bir etkinlik alanıdır. Bilişsel açıdan çocukların okumayı kazanma ve geliştirme süreçlerini anlamak için okumanın sosyal ve motivasyonel boyutlarını göz önünde bulundurmak gerekir (Monteiro, 2013). Yapılan araştırmalar, öğrencilerin okuma becerilerinin duyuşsal faktörlerden etkilendiğini ortaya koymaktadır (Cambria ve Guthrie, 2010; Guthrie ve ark., 2007; Wigfield, Gladstone ve Turci, 2016). Bu duyuşsal faktörlerden ikisi okuma motivasyonu ve tutumudur.

\section{Okuma Motivasyonu ve Tutumu}

Motivasyon, kişilerin sahip oldukları inançlar, değerler, ihtiyaçlar ve amaçlardır (Guthrie ve Wigfield, 1997). Okuma motivasyonu ise; ilgi, his, algı kontrolü, uyum, katılım, etkililik gibi çok yönlü bileşeni olan bir kavramdır (Guthrie ve ark., 2007). Okuma motivasyonu, çocukların okumaya yönelik zevklerini, isteklerini ve davranışlarını içerir (Cambria ve Guthrie, 2010). Wigfield (1997) okuma 
motivasyonunu, okuyucuların kendileri hakkındaki inançları, öz yeterlilik algıları, okuma başarısından beklentileri ve kendilerini bir okuyucu olarak nasıl algıladıklarına ilişkin düşünceleri olarak tanımlar.

Okuma motivasyonunun en önemli iki bileşeni okuyucu benlik algısı ve okumaya verilen değerdir. Okumaya yönelik benlik algısı, okuma sürecine ilişkin algılar olarak tanımlanabilir. Kişinin okuma sürecini nasıl gördüğü, okumaktan zevk alması, okumayı bir araç olarak kullanması, okumayı bir yaşam biçimi haline dönüştürmesi veya kitaplara ilişkin bakış açısı gibi çok değişik etkenler bu algıyı şekillendirir. Örneğin okuma sürecine yönelik algısı olumsuz olan öğrenciler, daha dikkatsiz, kararsız ve ne yapacağını bilemez bir halde olurlar. Bu durum bu öğrencilerin motivasyonlarını da etkiler (Henk, Marinak ve Melnick, 2013).

Okuyucu benlik algısı, okuma ve öğrenme sürecine yönelik öğrencilerin motivasyonlarını arttırabilir veya engelleyebilir (Schunk, 1982, Zimmerman ve Ringle, 1981). Okuyucu benlik algısı ve okuma başarısı arasında güçlü bir ilişki vardır (Chapman ve Tunmer, 2003). Bir okuyucu, okuyucu benlik algısına göre okuma sürecini şekillendirir. Bu bağlamda eğer olumlu bir algıya sahipse okuma için daha fazla çaba sarf eder, kitap ile daha çok zaman geçirir ve okuduğunu anlamak için daha ısrarcı olur (Henk ve Melnick, 1995).

Okuma motivasyonunun diğer bir boyutu olan okumaya verilen değer, okuyucuların günlük yaşamlarında okumaya ne kadar yer verdikleri ve ne sıklıkla okuma yaptıklarına dair bilgileri içeren bir kavramdır. Okumaya verilen değere ilişkin sorular, öğrencilerin okuma görevlerine, okuma etkinliklerine, okumayla uğraşma ve okuyarak vakit geçirme sıklıklarına verdikleri değeri ortaya koymak için tasarlanmıştır (Ataş, 2015).

Son yıllarda yapılan araştırmalar daha çok okuma ve yazma başarısı ile okuma becerisi zayıf olan öğrenciler üzerine yoğunlaşmasına rağmen bazı araştırmacılar, okuma ve yazmanın motivasyon boyutu ile öğrencilerin okuma motivasyonlarının okuduğunu anlamayla ilişkisi üzerinde çalışmaya başlamışlardır (Hamilton, Nolen ve Abbott, 2013; Wigfield ve ark., 2016). Çocukların okuma motivasyonları onların okuduğunu anlama becerileri ile ilişkilidir. Çocuklar okumaya motive oldukları zaman okuduklarını daha iyi anlarlar (Guthrie ve ark., 2007; Wigfield ve ark., 2016). Araştırmalar okuma becerileri ile okuma motivasyonun birlikte işlediğini ortaya koymaktadır. Genellikle okuma becerileri gelişen bir öğrencinin okuma motivasyonu da artar. Aynı şekilde okuma motivasyonu artan bir öğrencinin okuma becerilerinde gelişme gözlenir (Cambria ve Guthrie, 2010).

Okumaya ilişkin tutum ise, okuyucunun okuma tercihlerini, isteğini, yeterliliğini ve başarısını ve aynı zamanda akademik başarısını etkileyen karmaşık bir yapıdır (Pitcher ve diğ., 2007). Birçok değişkeni olan okuma tutumuna ilişkin kesin bir tanım yapmak zordur. Bu nedenle alan yazında okuma tutumu kavramını açıklayan çok değişik tanımlar vardır. Ancak son yıllarda okuma tutumuna 
yönelik yapılan tanımlar, öncelikli olarak okuyucunun duygularına ve hissettiklerine yoğunlaşmıştır (Kim, 2016). Bu bağlamda, okumaya ilişkin tutum, okumaya yönelik hissedilen duygular ve okumaya duyulan eğilim olarak ifade edilebilir. Eğer bu duygular olumlu yönde ise öğrenci daha bir okuyucu olmak için kendi isteğiyle okur (Chapman ve Tunmer, 1997; Schiefele ve ark., 2012).

Çocukların gelişimi ve hayat boyu öğrenmeleri için okumaya yönelik olumlu tutum geliştirilmesi de son derece kritik bir öneme sahiptir (Lee, 2014). Okumaya ilişkin tutum ile okuma başarısı arasında güçlü bir ilişki vardır. Aynı zamanda öğrencilerin okumaya ilişkin tutumları ve özgüvenleri, onların hem kelime okuma hem de anlama becerilerini yordar (McGeown ve ark., 2015).

Okumaya ilişkin tutumlar, yaşanan tecrübelere ve okuma ile ilgili deneyimlere dayalıdır. Bu deneyimler doğrudan ve dolaylı olarak kazanılabilir. Doğrudan kazanılan deneyimler, daha çok kişinin kendi okumasıyla ve okuma sürecine olan yaklaşımıyla ilgilidir. Dolaylı kazanımlar ise bir grup içerisinde edinilen yaşantılar ile ilgilidir. Burada aile, arkadaşlar veya öğretmenin sınıfta yapacağı grup çalışmaları söz konusudur (Broeder ve Stokmans, 2013).

Öğrencilerin okuma becerilerinin gelişimi için onların okuma tutumlarının ve motivasyonlarının olumlu yönde geliştirilmesi gerekir. Bu noktada öğretmenler son derece kritik bir öneme sahiptirler. Öğretmenler hem öğrencilerini okumaya motive etme hem de onların okumaya ilişkin tutumlarını geliştirme konusunda son derece etkilidirler. Öğrencilerin ilgilerine göre yapılacak okuma çalışmaları, grup çalışmaları ve etkinlikler okuma motivasyonlarının ve tutumlarının gelişmesine yardımcı olur (Fletcher ve ark., 2012). Bu bağlamda öğretmenin sınıfta kullanacağı okumaya yönelik yöntem, teknik veya stratejileri çok iyi seçmesi ve uygulaması gerekir (Kim, 2016). Öğrencilerin okumaya ilişkin motivasyonlarını ve tutumlarını geliştirmede etkili olabilecek yöntemlerden biri yaratıcı dramadır.

\section{Yaratıcı Drama ile Okuma Motivasyonu ve Tutumu}

Yaratıcı drama, imgesel olan düşünceleri eyleme dönüştürme sürecidir (Courtney, 1989). San'a (2002) göre yaratıcı drama, doğaçlama, rol oynama vb. tiyatro ya da drama tekniklerinden yararlanılarak, bir grup çalışması içinde, bireylerin bir yaşantıyı, bir olayı, bir fikri, kimi zaman bir soyut kavramı ya da bir davranışı, eski bilişsel örüntülerin yeniden düzenlenmesi yoluyla ve gözlem, deneyim, duygu ve yaşantıların gözden geçirildiği "oyunsu" süreçlerde anlamlandırılması, canlandırılmasıdır.

Yaratıcı drama, tümel bir öğrenmeyi gerçekleştirebilecek özelliklere sahiptir. Yaratıcı dramanın bir öğrenme yolu olarak en önemli varlığı; düşünsel, duygusal ve bedensel boyutlarıyla bütünleşmiş olmasıdır. Her öğrenme biçiminde bulunan pek çok beceri yaratıcı dramaya katılım 
yoluyla elde edilir. Katılımcılar eğitimde yaratıcı drama ile kendilerinin merkezde olduğu çeşitli dramatik süreçleri yaşarlar. (Adıgüzel, 2010, Üstündağ, 2010).

Yaratıcı drama, okuryazarlık becerilerinin gelişimi için son derece uygun bir yöntemdir. Okuryazarlık basit olarak sadece okuma ve yazma becerileri anlamına gelmez. Okuryazarlık, iletişim ve anlama becerilerini tüm yönleriyle ele alır. Drama da bu becerilerin gelişimine yardımcı olduğu için okuryazarlık sürecinde oldukça önemli bir yöntemdir ve bu süreçte çocuklara sosyal, zihinsel, duygusal ve kültürel fırsatlar sağlar (Baldwin ve Fleming, 2003).

Yaratıcı drama uygulamaları, dil kullanımını gerektiren gerçek ortamların yanı sıra eğitimde gerçeğe benzer bağlamlar yaratarak dil kullanımlarını çeşitlendirmenin bir yoludur. Doğal ortamlarıyla dil gelişimi için çocuklara katkı sağlar (Aktaş Arnas, Cömertpay ve Sofu, 2007). Yapılan araştırmalar da yaratıcı drama yönteminin katılımcıların dil becerilerini geliştirmede etkili olduğunu ve bu becerilere yönelik tutumlarını geliştirdiğini ortaya koymaktadır (Ataman, 2006; Aykaç, 2011; Erdoğan, 2013; Karateke, 2006; Kaya, 2008; Kırmızı, 2008; Stowe, 2001; Yıldırım ve Erdoğan, 2016; YıImaz, 2009).

Yaratıcı drama sürecinde yapılan etkinlikler, öğrencileri merkeze alarak dil becerilerini kullanmalarını sağlar. Türkçe derslerinde yaratıcı drama yönteminden yararlanılması ile öğrenciler derse etkin olarak katılabilirler. Sınıf ortamında, çocuk edebiyatı metinleriyle kurgulanan yaratıcı drama etkinlikleriyle, konuşan, okuyan, yazan, araştıran, sorgulayan ve eleştirel düşünebilen çok yönlü bireyler yetiştirilebilir (Aykaç, 2011).

Yaratıcı drama sürecinde çocuklar başkalarını dinleyerek onların kendilerini ifade etme süreçlerine tanık olurlar ve farklı amaçlar için nasıl konuşulduğunu gözlemlerler. Bununla birlikte drama sürecinde kullanılan metinler de çocukların okuma materyallerini tanımalarına ve bunlara ilgi duymalarına yardımcı olur. Dramada çocuklar, yaratıcı düşünme becerilerini ve hayal güçlerini de sürece dâhil ettiklerinde ortaya farklı metinler çıkar ve bu metinler çocukların okuma ve yazma becerilerini geliştirir (Baldwin ve Fleming, 2003).

Yılmaz'a (2009) göre oyunlarla ve yaratıcı drama teknikleriyle desteklenen yaratıcı okuma çalışmaları, çocukların kitaplara bakışını değiştirebilecek ve bu süreçten keyif almalarını sağlayacak çalışmalardan biridir. Bidwell (1992) yaptığı çalışmada dramanın öğrencilerin akıcı okuma ve okuma hızlarını geliştirdiğini, bununla birlikte en önemli gelişmenin motivasyonda olduğunu gözlemlemiştir. Yıldırım ve Erdoğan (2016) tarafından yapılan araştırmada da yaratıcı drama yönteminin ilkokul ikinci sınıf öğrencilerinin Türkçe dersine ilişkin tutumlarını olumlu etkilediği sonucuna ulaşımıştır.

\section{Araştırmanın Önemi ve Amacı}

Okumayla ilgili yapılan araştırmalar incelendiğinde, genel olarak okumanın bilişsel yönü üzerinde durulduğu görülmektedir. Okumanın duyuşsal yönüyle ilgili yapılan ve okuma motivasyonu 
ile tutumunu etkileyen değişkenlerin incelendiği deneysel çalışmaların sayısı oldukça azdır (Guthrie, McRae ve Klauda, 2007). Buna benzer olarak yaratıcı dramanın okuma motivasyonu ve tutumuna etkisi inceleyen araştırmaların sayısı da fazla değildir. Bu araştırma, öğrencilerin okumanın duyuşsal yönüyle ilgili yaratıcı drama yönteminin etkisini ortaya koyması bakımından önemlidir. Bu bağlamda araştırmanın sonuçlarının, öğrencilerin okuma motivasyonu ve tutumlarının geliştirilmesi açısından eğitimcilere yol göstereceği düşünülmektedir. Bu önemden hareketle yapılan araştırmanın amacı, yaratıcı drama yönteminin ilkokul 4. sınıf öğrencilerinin okuma motivasyonu ve tutumlarına etkisini belirlemektir.

\section{Hipotezler}

1. Araştırmaya katılan öğrencilerin okuma motivasyonu ölçeğinden aldıkları ön test ve son test puanları arasında anlamlı bir fark vardır.

2. Araştırmaya katılan öğrencilerin okuma tutum ölçeğinden aldıkları ön test ve son test puanları arasında anlamlı bir fark vardır.

\section{Yöntem}

\section{Araştırmanın Modeli}

Araştırmada "tek grup ön test-son test deneysel desen" kullanılmıştır. Bu desende deneysel işlemin etkisi tek bir grup üzerinde yapılan çalışmayla test edilir. Deneklerin bağımlı değişkene ilişkin ölçümleri uygulama öncesinde ön test, sonrasında son test olarak aynı denekler ve aynı ölçme araçları kullanılarak elde edilir (Büyüköztürk ve diğerleri, 2013). Bu bağlamda araştırmada öğrencilerin uygulama öncesinde ve sonrasında okuma motivasyonları ve tutumları ilgili ölçme araçları kullanılarak belirlenmiştir. Elde edilen verilerin toplanması, analizi ve yorumlanmasında nicel araştırma yöntemi kullanılmıştır.

\section{Çalışma Grubu}

Araştırmanın çalışma grubunu 2015-2016 eğitim-öğretim yılında Trabzon ilindeki bir belde okulunda ilkokul 4. sınıfta öğrenim gören 16 öğrenci oluşturmaktadır. Araştırmaya katılan öğrencilerden 10’ kız, 6’sı erkektir. Öğrencilerin yaşları 8-9 arasındadır. Öğrencilerin yaratııı dramayla ilgili herhangi bir ön yaşantıları yoktur.

\section{Veri Toplama Araçları}

Araştırmada, öğrencilerin okumaya ilişkin motivasyonlarını belirlemek için Yıldız (2013) tarafından Türkçeye uyarlanan Okuma Motivasyonu Profili (OMP) Ölçeği kullanılmıştır. OMP, ilköğretim ikinci sınıftan altıncı sınıfa kadar uygulanabilen, 20 maddelik Okuma Anketi ile 14 soruluk görüşme formu olmak üzere iki temel araçtan oluşmaktadır. Okuma Anketi, okumaya verilen değer 
(10 soru) ve okuyucu benlik algısı (10 soru) olmak üzere iki faktörden oluşmaktadır. Türkçeye uyarlanan OMP ölçeğinin güvenirlik çalışmaları sonucunda faktör yük değeri düşük olan iki madde ölçekten çıkarıldıktan sonra 18 maddelik nihai anket formuna ulaşılmıştır. Araştırmada Okuma Motivasyonu Profili (OMP) Ölçeği'nin "okuma motivasyonu” bölümü kullanılmıştır. Ölçeğin geçerlik ve güvenirlik çalışmaları Yıldız (2013) tarafından yapılmıştır. Güvenirlik düzeyi test-tekrar test tekniği ve iç tutarlılık katsayısı hesaplanarak belirlenmiştir. Diğer uyum indekslerinin de kabul edilebilir sınırlarda (RMSEA=0.070, RMR=036, GFI=.85) olduğu tespit edilmiştir. Ölçümlerin güvenirliğine ilişkin Cronbach's Alpha katsayısı .81'dir. Bu durum Okuma Ölçeği-Türkçe Formu'nun geçerli bir yapıya ve güvenilir ölçümler yapabilecek niteliğe sahip olduğunu göstermektedir (Yıldız, 2013).

Araştırmada, öğrencilerin okumaya ilişkin tutumlarını belirlemek için ise Susar Kırmızı (2008) tarafından geliştirilen “Okumaya Yönelik Tutum Ölçeği” kullanılmıştır. Ölçek, 32 maddeden oluşmakta ve bu maddelere ilişkin öğrencilerin katılma düzeylerini belirlemek amacıyla Likert tipi "Tamamen Uygun, Oldukça Uygun, Kısmen Uygun, Çok Az Uygun, Hiç Uygun Değil” şeklinde beşli derecelendirme yapılmıştır. Ölçeğin tümü göz önüne alındığında Cronbach's Alpha 0,83 olarak tespit edilirken, iki yarı güvenirlik katsayısı ise 0,77 olarak elde edilmiştir.

İşlem

Araştırmada öğrencilere Türkçe dersi kapsamında yaratıcı drama yöntemiyle okuma çalışmaları yaptırılmıştır. Yaptırılan çalışmalar yaratıcı drama eğitmeni olan Erdoğan (2015) tarafından hazırlanmıştır. Uygulama, 30 ders saati sürmüştür. Bu süre içerisinde 7 farklı uygulama yapılmıştır. Yapılan uygulamalar ve örnek bir uygulama şu şekildedir: (i) Bulutlar Üstünde Bir Kent (ii) Balonlardaki Sorular (iii) Fabrikadaki Ayı (iv) Harfler Neden Yok? (v) İki Küçük Su Damlası (vi) Kırmızı Fil Nerede? (vii) Son Baskı

\section{Örnek Uygulama: Balonlardaki Sorular}

Tema: Hayal Gücü

Önerilen Süre: 4 ders saati

Kazanımlar:

1. Akıcı okur.

2. Okuduğu metne yönelik sorular sorar.

3. Konuşmalarında karşıllaştırmalar yapar.

Yöntem ve Teknikler: Yaratıcı Drama (doğaçlama, rol oynama, geriye dönüş).

Araç ve Gereçler: Aytül AKAL'ın “Soru Balonları” adlı kitabı, balonlar (sarı, kırmııı, mavi, yeşil, beyaz, kırmızı), müzik $C D$ 'si, $C D$ çalar. 
Süreç

A. Isınma-Hazırlık

1. Etkinlik: Lider, öğrencilere farklı renklerde birer tane balon verir ve hareketli bir müzik açar. Öğrenciler, müzik eşliğinde balonlarla oynamaya başlarlar ve balonları yere düşürmemeye çalışırlar. Bir süre sonra öğrenciler sırayla; ellerini kullanmadan, sonra ellerini ve ayaklarını kullanmadan balonlarla oynarlar. En son aşamada ise sırayla vücutlarının bir bölümünü kullanarak balonlarla oynamaya devam ederler.

2. Etkinlik: Lider, öğrencilere, "Soru Balonları" kitabının giriş bölümünü okur. Öğrencilere küçük kâğıtlar dağıtır. Tahtaya "güneş, ormanlar, denizler, toprak, şehirler, hayvanlar vb." kelimeleri yazar. Öğrenciler, minik gezegende yaşayan çok meraklı çocukların bu konularla ilgili neler sorabileceklerini düşünürler. Daha sonra bu konulardan birini seçerler ve bu konuyla ilgili merak ettikleri bir konuyu soru olarak kâğıtlara yazarlar. Öğrencilerle birlikte yazdıkları sorular konularına göre gruplanarak uygun renkteki balonların üstüne yapıştırılır. Her öğrenci yazdığı sorunun olduğu balonu alır ve müzikle birlikte hareket etmeye başlar. Bir süre sonra müzik devam ederken çocuklar balonları birbirleriyle değiştirirler. Lider, müziği durdurur ve öğrenciler sırasıyla ellerinde olan balondaki soruyu yüksek sesle okur ve soruya cevap verirler.

Ara Değerlendirme: Öğrencilerle, soru sormanın ve bu soruların cevaplarını araştırmanın çocuklara ne gibi faydalar sağlayacağı konusunda konuşulur.

B. Canlandirma

3. Etkinlik: Lider, öğrencilerden gözlerini kapatmalarını ve aşağıda söylenen durumları hayal etmelerini ister.

"Elinizde uçan bir balon var. Onu yavaş yavaşs şişiriyorsunuz. Balonunuz gittikçe büyüyor. Şimdi kocaman oldu. Sizi kaldırabilecek kadar büyüdü balonunuz. Balonunuzun ipinden tutuyorsunuz. Ve gökyüzüne yükselmeye başllyorsunuz. Evler, insanlar gittikçe küçülüyor. Yanınızdan kuşlar geçiyor. Onlara gülümsüyorsunuz. Bulutları görüyorsunuz. Bembeyaz bulutları. Dokunuyorsunuz onlara. Çok mutlusunuz. Bu balon sizi farklı bir gezegene götürüyor. Bu gezegende milyonlarca çocuk var. Ama bu çocuklar bir ekranın karşısında saatlerce kıpırdamadan oturuyor. Ve bu gezegenin atmosferinde soru balonları uçmuyor. Çok şaşırıyorsunuz...Çocukların raflarında sıra sıra kitaplar var ama çoğuna dokunulmuyor. Çocuklar bu gezegende çok fazla soru sormuyor, sormadıkları için de kimse merak edip kitapları karıştırmıyor..." 
Öğrenciler, yavaşça gözlerini açarlar ve ikili grup oluştururlar. Gruplardaki öğrencilerden biri A, diğeri B olarak belirlenir. A’lar "Soru Balonları" kitabında anlatılan minik gezegende yaşayan, sürekli soru soran ve soruların cevaplarını kitaplarda araştıran bir çocuk; B’ler ise diğer gezegende yaşayan, soru sormayan ve kitap okumayan bir çocuk olurlar. Lider, A'ların B'lerin yaşadığı gezegene geldiğini ve B'lerle karşılaştı̆̆ını söyler. Öğrencilerden bu iki çocuk arasında geçen konuşmayı doğaçlamalarını ister.

4. Etkinlik: Öğrenciler dört gruba ayrılır. Birinci grup, soru soran ve kitap okuyan çocukların olduğu gezegendeki çocukların; ikinci grup soru sormayan ve kitap okumayan çocukların olduğu gezegendeki çocukların günlük yaşamıyla; üçüncü grup ilk gezegende; dördüncü grup ise ikinci gezegende on yıl sonra neler olabileceğiyle ilgili bir doğaçlama hazırlar. Grupların hazırladıkları doğaçlamalar sırayla izlenir. Öğrenciler, doğaçlamalarda sunulan iki farklı gezegendeki yaşamla ilgili görüşlerini ifade ederler ve bu iki gezegeni karşılaştırırlar. Daha sonra kitabın son bölümünü okurlar.

C. Değerlendirme-Tartışma

5. Etkinlik: Öğrencilerden, sürekli soru soran ve bu soruların cevaplarını bulmak için araştırma yapan çocukların yaşadığı gezegeni anlatan betimleyici bir yazı yazmaları istenir. Gönüllü öğrenciler, yazdıkları yazıları arkadaşlarıyla paylaşırlar.

6. Etkinlik: Öğrenciler, "Soru Balonları" kitabıyla ilgili birer tane soru yazarlar. Öğrenciler yazdıkları soruları okurlar ve diğer öğrenciler cevaplandırırlar.

\section{Verilerin Toplanması ve Analizi}

Araştırmada öğrencilerin uygulamanın başında ve sonunda okumaya ilişkin motivasyonlarını ve tutumlarını belirlemek için "Okuma Motivasyonu Profili Ölçeği" ve "Okuma Tutum Ölçeği" uygulanmıştır. Öğrencilerin ölçeklerden aldıkları puanlar arasında istatistiksel olarak anlamlı bir fark olup olmadığını belirlemek için öğrenci sayısı ve ölçeklerin yapısı dikkate alınarak "Wilcoxon İşaretli Sıralar Testi" kullanılmıştır. Wilcoxon İşaretli Sıralar Testi, ilişkili iki ölçüm setine ait puanlar arasındaki farkın anlamlıı̆ı̆ını test etmek amacıyla kullanılır (Büyüköztürk, 2006).

\section{Bulgular ve Yorum}

Birinci Hipoteze Ilişsin Bulgular ve Yorum

Araştırmada öğrencilerin “Okuma Motivasyonu Profili Ölçeği'nin “Okuyucu Benlik Algısı” ve "Okumaya Verilen Değer" boyutlarından aldıkları ön test ve son test puanlarının ortalamaları arasında anlamlı bir fark olup olmadığı "Wilcoxon İşaretli Sıralar Testi” ile analiz edilmiştir. Öğrencilerin aldıkları puanların ortalamaları arasında anlamlı bir fark olup olmadığına ilişkin sonuçlar Tablo 1'de verilmiştir. 
Tablo 1. Öğrencilerin "okuma motivasyonu profili ölçeği"nden aldıkları ön test ve son test puanlarının wilcoxon işaretli sıralar testi sonuçları

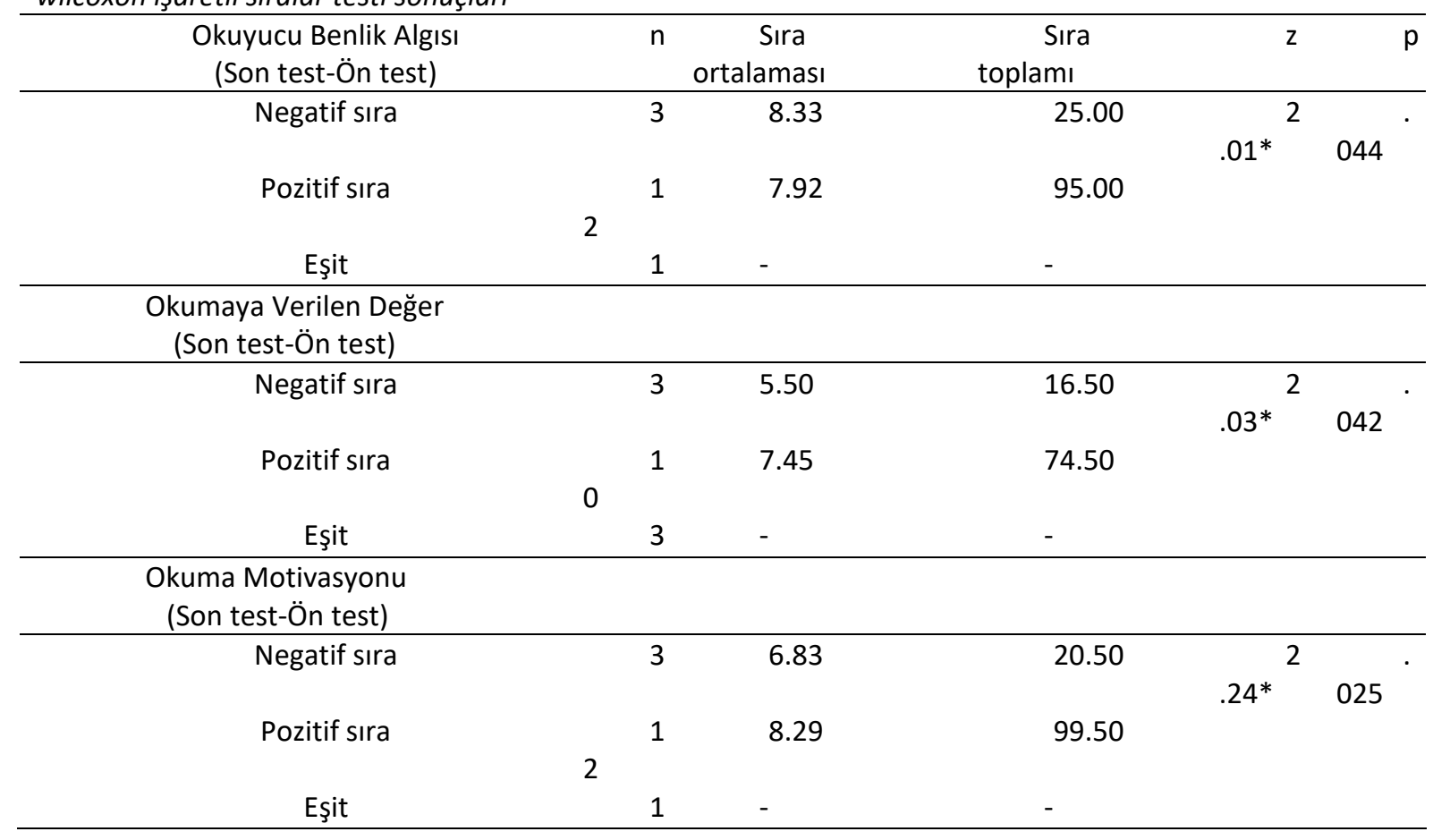

*Negatif sıralar temeline dayalı

Tablo 1'deki verilere göre, öğrencilerin uygulama öncesinde ve sonrasında "Okuma Motivasyonu Profili Ölçeği"nin alt boyutları ve toplamından aldıkları puanlar arasında istatistiksel olarak anlamlı bir fark olduğu görülmektedir $(p<.05)$. Fark puanlarının sıra ortalaması ve toplamları dikkate alındığında bu farkın pozitif sıralar yani son test puanları lehine olduğu görülmektedir. Araştırmada elde edilen bu bulgu, yaratıcı drama yönteminin öğrencilerin okuma motivasyonlarını olumlu etkilediğini ortaya koymaktadır.

ikinci Hipoteze Ilişkin Bulgular ve Yorum

Araştırmada öğrencilerin “Okumaya Yönelik Tutum Ölçeği’nden aldıkları ön test ve son test puanlarının ortalamaları arasında anlamlı bir fark olup olmadığı "Wilcoxon İşaretli Sıralar Testi" ile analiz edilmiştir. Öğrencilerin aldıkları puanların ortalamaları arasında anlamlı bir fark olup olmadığına ilişkin sonuçlar Tablo 2'de verilmiştir.

Tablo 2. Öğrencilerin "okuma tutum ölçeği"nden aldıkları ön test ve son test puanlarının wilcoxon işaretli sıralar testi sonuçları

\begin{tabular}{llcccc}
\hline Tutum (Son test-Ön test) & $\mathrm{n}$ & Sıra ortalaması & Sıra toplamı & $\mathrm{z}$ & $\mathrm{p}$ \\
\hline Negatif Sıra & 7 & 8.29 & 58.00 & &. \\
& & & 62.00 & & 909 \\
Pozitif Sıra & 8 & 7.75 & & \\
Eşit & 1 & & & \\
\hline
\end{tabular}

*Negatif sıralar temeline dayalı 
Tablo 2'deki verilere göre, öğrencilerin uygulama öncesinde ve sonrasında "Okuma Tutum Ölçeği”nden aldıkları puanlar arasında istatistiksel olarak anlamlı bir fark olmadığı görülmektedir ( $p>$.05). Araştırmada elde edilen bu bulgu, yaratıcı drama yönteminin öğrencilerin okuma tutumlarını etkilemediğini ortaya koymaktadır.

\section{Tartışma, Sonuç ve Öneriler}

Araştırmada elde edilen sonuçlar, yaratıcı drama yönteminin öğrencilerin okuma motivasyonlarını olumlu etkilediğini ortaya koymaktadır. De Naeghel ve Van Keer' e (2013) göre sınıf ortamında yapılan ilgi çekici etkinlikler ve çalışmalar öğrencilerin okuma motivasyonlarını başarılı bir şekilde arttırmak için oldukça önemlidir. Bu nedenle çocukları okumaya motive etmek için, sınıfta okumanın teşvik edildiği bir ortam yaratılmalıdır (Monteiro, 2013). Yaratıcı drama sürecinde öğrenciler ısınma-hazırlık aşamasında okuyacakları metin veya kitapla ilgili çeşitli etkinlikler yaparlar. Yapılan bu etkinliklerle fiziksel, bilişsel ve duyuşsal olarak okuma sürecine hazırlanırlar ve okuma süreci için istekli hale gelirler. Daha sonra metinle ilgili yaratıcı dramanın farklı tekniklerini kullanarak canlandırma çalışmaları yaparlar. Adomat'a (2012) göre sınıfta yaptırılan bu drama çalışmaları, öğrencilerin okuma metnini daha derinlemesine incelemelerine ve anlamalarına yardımcı olur. Drama ile bütünleşen okuma süreci, öğrencilerin okumaya olan bağılıklarını arttırır. Bu durum da öğrencilerin okuyucu benlik algılarını ve okumaya verdikleri değeri olumlu etkiler.

Drama sürecinde öğrenciler sıkıcı, monoton etkinlikler yerine özgün, eğlenceli ve düşündürücü etkinlikler yaparlar (Tandy ve Howell, 2010). Olaylara, durumlara farklı yönlerden bakar ve bunlar üzerinde derinlemesine düşünürler. Bu bağlamda, yaratıcı drama, aktif anlam çıkarma süreci olan okumayı destekler. Çünkü bir role girerek ve metin üzerinde düşünerek öğrencilerin birçok farklı bakış açısı geliştirmelerine yardımcı olur. Bu farklı bakış açıları ve görüşler, metin dışı anlam kurmaya da yardımcı olur. Bu süreçte metin ve okuma materyalleriyle daha uzun süre iç içe olan öğrenci aynı zamanda okumaya olan bakış açısını değiştirir (Wilhelm, 2007). Bu araştırmada da yaratıcı drama yöntemiyle yapılan okuma çalışmalarının öğrencilerin metni daha iyi anlamlandırmasını sağladığı ve okuma süreçlerini desteklediği düşünülmektedir. Bu durum öğrencilerin okuma motivasyonlarını olumlu etkilemektedir.

Yaratıcı drama süreci, birçok dil becerisinin ve düşünme becerisinin etkin kullanımını gerektirir. Drama sürecinde kullanılan bu beceriler aynı zamanda okuma süreci için de kritik öneme sahiptir. Çünkü drama süreci içinde bulunan bir çocuk, bu süreçte okunan kitabın tüm detaylarını rahatlıkla açıklayabilir. Metnin konusu, karakterleri, oluş sırası, neden-sonuç ilişkileri gibi öğeleri istenen şekilde ifade edebilir. Drama ile yapılan etkinlikler sayesinde yorumlama ve anlam çıkarma 
becerisi gelişir. Tüm bu yeterlilikler, okunan metni benimsemeye ve daha derinden hissetmeye yardımcı olur (Wilhelm 2002).

Yaratıcı drama sürecinde öğrenciler ilgilerini çeken ve amaçlarına uygun konular üzerine okuma becerileriyle ilgili çalışmalar yaparlar. Öğrencilerinin ilgilerini bilen bir öğretmen, sınıfta kullanacağı okuma materyalini buna göre seçer ve bu materyal üzerinde daha eğlenceli çalışmalar yapabilir. Öğrencilerin ilgilerine göre verilen okuma etkinlikleri, onların eğlenmelerini sağlar. Bu durum öğrencilerin okumaya yönelik ilgilerinin ve motivasyonlarının artmasına yardımcı olur (Merisuo-Storm, 2006; Pitcher ve ark., 2007). Bu araştırmada da yaratıcı drama yöntemiyle yapılan okuma çalışmaları öğrencilerin ilgilerine yönelik olarak hazırlanmış ve uygulanmıştır.

Drama sürecinde katılımcılar okuma becerileriyle ilgili etkinlikleri rahat ve özgür bir ortamda gerçekleştirirler. Ayrıca okuma süreci içinde merak ve heyecan gibi unsurlar yer alır. Böylece öğrencilerin hayal güçlerinin harekete geçirilmesi sağlanır. Öğrenciler drama sürecinde kendilerinin etkin olduğu bir eğitim ortamı yaşarlar. Yaşadıkları farklı deneyimler onlara duyuşsal anlamda olumlu etkiler yapar. Böylece okumaya ilişkin algıları, verdikleri değer ve dolayısıyla motivasyonları artar.

Lee (2014), yaptığı araştırmada grup ile birlikte yapılan okuma etkinliklerinde öğrencilerin metni daha iyi kavradıklarını ve metinle ilgili görevleri daha doğru bir şekilde yerine getirdiğini ileri sürmektedir. Ayrıca grup çalışması ile akranlarıyla iletişim halinde olan öğrencilerin daha çok eğlendiklerini, okumaya daha çok motive olduklarını ve okumaya ilişkin tutumlarının yükseldiğini gözlemiştir. Yaratıcı drama da bir grup etkinliğidir. Bu süreçte öğrenciler birbirleriyle etkileşim kurarlar. Yaptıkları grup çalışmalarıyla okuma öncesi, sırası ve sonrasında olaylar, durumlar üzerinde düşünür ve fikir alışverişinde bulunurlar. Bu süreç onların birlikte öğrenmelerini, eğlenmelerini ve okuma sürecinden keyif almalarını sağlar. Ayrıca bu süreçte öğrenciler kendilerini yalnız hissetmezler. Böylece okuma sürecinde olumsuz duygular yaşamazlar. Araştırmada yapılan uygulamalarda grup çalışmalarından etkin bir şekilde yararlanılmıştır. Öğrencilerin grup çalışmalarına aktif bir şekilde katılımı sağlanarak okuma süreci desteklenmiştir. Yaratıcı drama sürecinden yapılan bu grup çalışmalarının da öğrencilerin motivasyonlarını olumlu etkilediği söylenebilir.

Araştırmada elde edilen diğer bir sonuç ise, yaratıcı drama yönteminin öğrencilerin okumaya ilişkin tutumlarını etkilemediğidir. Schiefele ve arkadaşlarına (2012) göre okumaya ilişkin tutum, değerler, iç motivasyon, inançlar, amaçlar, bakış açısı, hırsıı olma, merak bağlılık gibi birçok değişkeni içerir. Bu bağlamda tutum çok boyutlu ve karmaşık bir kavramdır. Tutumların değişmesi uzun bir süreç gerektirmektedir. Araştırmada öğrencilerinin okumaya yönelik tutumlarının geliştiği ancak anlamlı bir farkın oluşmadığı görülmektedir. Bu durum, uygulama sürecinin okumaya ilişkin tutumu geliştirecek kadar uzun olmamasıyla açıklanabilir. Nitekim Susar Kırmızı (2008) tarafından yapılan 
araştırmada da benzer sonuçlara ulaşılmıştır. Susar Kırmızı (2008) tarafından yapılan araştırmada okumaya yönelik tutuma ilişkin olarak son testlerin sonucuna göre, yaratıcı drama ve Türkçe dersi öğretim programına göre öğrenme grupları arasında farkın önemsiz olduğu tespit edilmiştir. Okumaya yönelik tutumda anlamlı bir farklılık çıkmamış olması uygulama süresinin sınırlı olması ile ilişkilendirilebileceği belirtilmiştir. Bu durum, herhangi bir duruma ya da konuya ilişkin tutum geliştirmenin oldukça uzun zaman gerektirebileceğiyle açıklanmıştır. Bunun yanında Yılmaz (2008) tarafından yapılan araştırmada ise sekiz hafta (12 saat) süren yaratıcı okuma uygulamaları sonucunda çocukların okuma tutumlarının olumlu yönde değişmeye başladığı görülmüştür. Bir başka deyişle, yaratıcı okuma uygulamaları sonrasında çocuklar kitaplardan ve okuma-anlama etkinliklerinden daha fazla hoşlanma eğilimi göstermişler, okuma süreci ile ilgili kaygıları azalmış ve okuma-anlama konusunda kendilerini daha yeterli hissetmeye başlamışlardır. Ancak çalışmada çok yönlü düşünmeyi öğretmek, düş gücünü geliştirmek elbette çok daha uzun soluklu çalışmalar gerektirdiği belirtilmiştir.

Araştırmada elde edilen sonuçlar ışığında ilkokuldaki okuma öğretimine ve sonraki araştırmalara yönelik olarak şu öneriler getirilebilir:

1. Türkçe derslerinde öğrencilerin okuma motivasyonlarını arttırmak için yaratıcı drama yönteminden yararlanılmalıdır.

2. Öğrencilerin okumaya ilişkin tutumlarını arttırmak için yaratıcı drama yöntemiyle daha uzun süreli çalışmalar yapılmalıdır.

3. Benzer çalışmalar farklı sınıf düzeylerinde ve farklı çalışma gruplarıyla yapılmalıdır.

4. Yaratıcı drama yönteminin diğer dil becerilerine ve bu becerileri etkileyen faktörlere etkisi araştırılmalıdır.

\section{Kaynaklar}

Adıgüzel, Ö. (2010). Eğitimde yaratıcı drama. Ankara: Natürel Yayınları.

Adomat, D. S. (2012). Drama's potential for deepening young children's understandings of stories. Early Childhood Education Journal, 40, 343-350. http://dx.doi.org/ 10.1007/s10643-012-0519-8

Aktaş Arnas, Y., Cömertpay B. \& Sofu, H. (2007). Altı yaş grubu çocukların dil kullanımına yaratıcı dramanın etkisi. Yaratıcı Drama Dergisi,1 (3-4), 7-26.

Akyol, H. (2012). Türkçe ilk okuma yazma öğretimi. (10. Baskı). Ankara: Pegem Akademi.

Ataman, M. (2006). Yaratıcı drama sürecinde yaratııı yazma. Yaratıcı Drama Dergisi,1 (1), 75-88.

Ataş, M. (2015). Illkokul öğrencilerinin okuma motivasyonlarıın bazı değişkenler bakımından incelenmesi. (Yüksek Lisans Tezi., Karadeniz Teknik Üniversitesi, Eğitim Bilimleri Enstitüsü, Trabzon). https://tez.yok.gov.tr/UlusalTezMerkezi/ adresinden edinilmiştir.

Aykaç, M. (2011). Türkçe öğretiminde çocuk edebiyatı metinleriyle kurgulanan yaratıcı drama etkinliklerinin anlatma becerilerine etkisi. (Doktora Tezi. Ankara Üniversitesi, Ankara). https://tez.yok.gov.tr/UlusalTezMerkezi/ adresinden edinilmiştir. 
Baldwin, P., \& Fleming, K. (2003). Teaching literacy through drama: Creative approaches. London: Routledge.

Bidwell, S. M (1992). Ideas for using drama to enhance reading instruction. The Reading Teacher. 45 (8), $653-$ 654.

Broeder, P., \& Stokmans, M. (2013). Why should I read?: A cross-cultural investigation into adolescents' reading socialisation and reading attitude. International Review of Education, 59 (1), 87-112. http://dx.doi.org/ $10.1007 / \mathrm{s} 11159-013-9354-4$

Burns, P. C., Roe B. D., \& Ross, E. P. (1992). Teaching reading in today's elemantary schools. New Jersey: Houghton Mifflin Company.

Büyüköztürk, Ş. (2006). Sosyal bilimler için veri analizi el kitabı. Ankara: PegemA Yayıncılık.

Büyüköztürk, Ş., Çakmak, E. K., Akgün, Ö. E., Karadeniz, Ş. \& Demirel, F. (2009). Bilimsel araştırma yöntemleri. Ankara: Pegem Akademi Yayınları.

Cambria, J., \& Guthrie, J. T. (2010). Motivating and engaging students in reading. The Nera Journal, 46(1), 1629.

Chapman, J. W., \& Tunmer, W. E. (2003). Reading difficulties, reading-related self-perceptions, and strategies for overcoming negative self-beliefs. Reading \& Writing Quarterly, 19(1), 5-24. http://dx.doi.org/10.1080/10573560308205

Chapman, J. W., \& W. E. Tunmer (1997). A longitudinal study of beginning reading achievement and reading self-concept. British Journal of Educational Psychology, 67, 27-291. http://onlinelibrary.wiley.com/doi/10.1111/j.2044-8279.1997.tb01244.x/pdf

Courtney, R. (1989). Culture and the creative drama teacher. Youth Theatre Journal, 3 (4), 18-23.

Çelenk, S. (2007). Illkokuma yazma programı ve öğretimi. Ankara: Maya Akademi.

De Naeghel, J., \& Van Keer, H. (2013). The relation of student and class-level characteristics to primary school students' autonomous reading motivation: A multi-level approach. Journal of Research in Reading, 36(4), 351-370. http://dx.doi.org/ 10.1111/jrir.12000

Denton, C. A., \& Al Otaiba, S. (2011). Teaching word identification to students with reading difficulties and disabilities. Focus on Exceptional Children, 43(7), 1-16.

Fletcher, J., Grimley, M., Greenwood, J., \& Parkhill, F. (2012). Motivating and improving attitudes to reading in the final years of primary schooling in five New Zealand schools. Literacy 46(1), 316. http://dx.doi.org/ 10.1111/j.1741-4369.2011.00589.x

Guthrie, J. T., McRae, A., \& Klauda, S. L. (2007). Contributions of concept-oriented reading instruction to knowledge about interventions for motivations in reading. Educational Psychologist, 42(4), 237-250. http://dx.doi.org/10.1080/00461520701621087

Guthrie, J. T., W, Hoa, A. L., Wigfield, A., Tonks, S. M., Humenick, M. N., \& Littles, E. (2007). Reading motivation and reading comprehension growth in the later elementary years. Contemporary Educational Psychology 32, 282-313. http://dx.doi.org/10.1016/j.cedpsych.2006.05.004

Guthrie, J. T., \& Wigfield, A. (1997). Reading engagement: A rationale for theory and teaching. In J.T. Guthrie \& A. Wigfield (Eds.), Reading engagement: Motivating readers through integrated instruction (pp. 1-12). Newark, DE: International Reading Association.

Hamilton, E. W., Nolen, S. B., \& Abbott, R. D. (2013). Developing measures of motivational orientation to read and write: A longitudinal study. Learning and Individual Differences, 28, 151-166. http://dx.doi.org/10.1016/j.lindif.2013.04.007

Harris, A. J., \& Sipay. E. R. (1990). How to increase reading ability. (Ninth Edition). New York: Longman.

Henk, W. A., Marinak, B. A, \& Melnick, S. A. (2013). Measuring the reader self-perceptions of adolescents, Journal of Adolescent \& Adult Literacy, 56(4), 311-320. http://dx.doi.org/ 10.1002/JAAL.00144 
Henk, W., \& Melnick, S. (1995). The reader self-perception scale (RSPS): A new tool for measuring how children feel about themselves as readers. The Reading Teacher, 48, 470-482. http://www.jstor.org/stable/20201471

Hollingsead, C., \& Ostrander, R. (2006). How can I help my students who struggle with reading comprehension?. Journal of Adventist Education, April/ May, 15-20.

Karateke, E. (2006). Yaratıcı dramanın ilköğretim II. kademede 6.sınıf öğrencilerinin yazılı anlatım becerilerine olan etkisi. (Yüksek Lisans Tezi, Mustafa Kemal Üniversitesi, Sosyal Bilimler Enstitüsü, Hatay). https://tez.yok.gov.tr/UlusalTezMerkezi/ adresinden edinilmiştir.

Kaya Güler, I. (2008). Illköğretim dördüncü sınıf Türkçe dersinde yaratıcı dramanın etkililiği. (Yüksek Lisans Tezi, On Dokuz Mayıs Üniversitesi, Samsun). https://tez.yok.gov.tr/UlusalTezMerkezi/ adresinden edinilmiştir.

Kırmızı, F. S. (2008). Türkçe dersinde yaratıcı drama yöntemine dayalı yaratıcı yazma çalışmalarının yazmaya yönelik tutuma etkisi. Yaratıcı Drama Dergisi, 4 (7), 51-68.

Kim, H. (2016). The relationships between Korean university students' reading attitude, reading strategy use, and reading proficiency, Reading Psychology, 37(8), 1162-1195. http://dx.doi.org/10.1080/02702711.2016.1193581

Lee, Y. (2014). Promise for enhancing children's reading attitudes through peer reading: A Mixed method approach. The Journal of Educational Research, 107(6), 482-492. http://dx.doi.org/10.1080/00220671.2013.836469

Merisuo-Storm, T. (2006). Girls and boys like to read and write different texts. Scandinavian Journal of Educational Research, 50(2), 111-125.

Monteiro, V. (2013). Promoting reading motivatıon by reading together. Reading Psychology, 34, 301-335. http://dx.doi.org/10.1080/02702711.2011.635333

Pitcher, S. M., Albright, L. K., DeLaney, C. J. , Walker, N. T., Seunarinesingh, K., Mogge, S., Headley, K. N., Ridgeway, V. G., Peck,S., Hunt, R., Dunston, P. J. (2007). Assessing adolescents' motivation to read. Journal of Adolescent \& Adult Literacy, 50, 378-396. http://dx.doi.org/ 10.1598/JAAL.50.5.5

McGeown, S. P., Johnston, R. S., Walker, J. , Howatson, K., Stockburn, A., \& Dufton, P. (2015). The relationship between young children's enjoyment of learning to read, reading attitudes, confidence and attainment. $\quad$ Educational 389-402. http://dx.doi.org/10.1080/00131881.2015.1091234

Razon, N. (1982). Okuma alışkanlığında öğretmenlerin rolü. Eğitim ve Bilim Dergisi, 7, 19-23.

San, ì. (2002). Yaratıcı dramanın-eğitsel boyutları. Yaratıcı Drama 1985-1998 Yazılar (2. Baskı), (Edt.: Ömer ADIGUZEL). Ankara: Naturel Yayınları.

Schiefele, U., Schaffner, E., Moller, J., \& Wigfield, A. (2012). Dimensions of reading motivation and their relation to reading behavior and competence. Reading Research Quarterly, 47(4), 427-463. http://onlinelibrary.wiley.com/doi/10.1002/RRQ.030/abstract

Schunk, D. H. (1982). Effects of effort attributional feedback on children's perceived self-efficacy and achievement. Journal of Educational Psychology, 74(4), 548-556. http://dx.doi.org/ 10.1037/00220663.74.4.548

Small, R. V., \& Arnone, M. P. (2011). Creative reading, Knowledge Quest, 39(4), 12-15.

Stowe, A. (2001). Using drama to improve creative writing. Retrieved from http://www.ntrp.org.uk/sites/all/documents/Stowe.pdf 12 April 2012.

Sylva, K., \& Hurry, J. (1996). Early intervention in children with reading difficulties: An evaluation of reading recovery and a phonological training. Literacy, Teaching and Learning, 2(2), 49-68.

Tandy, M. ve Howell, J. (2010). Creating drama with 7-11 year olds. USA: Routledge 
Üstündağ, T. (2010). Yaratıcı drama öğretmenimin günlüğü. (9. Baskı). Ankara: PegemA Yayıncılık.

Yıldız, M. (2013). Okuma motivasyonu profilinin Türkçe'ye uyarlanması: Geçerlik ve güvenirlik çalışması, 12. Sınıf Öğretmenliği Sempozyumu, Adnan Menderes Üniversitesi, Aydın.

Wilhelm, J. D. (2002). Action strategies for deepening comprehension. New York: Scholastic.

Wilhelm, J. D. (2007). You gotta BE the book: Teaching engaged and reflective reading with adolescents (2nd ed.). New York: Teachers College Press.

Wigfield, A. (1997). Children's motivations for reading and reading engagement. In J. Guthrie \& A. Wigfield (Eds.), Reading engagement (pp. 14-33). Newark, DE: International Reading Association.

Wigfield, A., Gladstone, J. R., \& Turci, L. (2016). Beyond cognition: Reading motivation and reading comprehension. Child Development Perspectives, 10(3), 190-195. http://dx.doi.org/ 10.1111/cdep.12184

Yııdırım, M. \& Erdoğan, T. (2016). Yaratıcı drama yönteminin ilkokul ikinci sınıf öğrencilerinin Türkçe dersine ilişkin tutumlarına etkisi. Yaratıcı Drama Dergisi, 11(1), 71-88.

YıImaz, N. (2009). Yaratıcı drama destekli yaratıcı okuma programı. Yaratıcı Drama Dergisi, 4(7), 1-28.

Zimmerman, B. J., \& Ringle, J. (1981). Effects of model persistence and statements of confidence on children's self-efficacy and problem solving. Journal of Educational Psychology, 73(4), 485-493. http://dx.doi.org/10.1037/0022-0663.73.4.485

\section{Extended Abstract}

Introduction

When the research on reading is examined, it is observed that generally the cognitive aspect of reading is mentioned. The number of experimental studies carried out on affective aspect of reading, in which variables affecting reading motivation and attitude are quite a few (Guthrie, McRae \& Klauda, 2007). Likewise, there a few searches examining the effect of creative drama on reading motivation and attitude. This research is important as it reveals the effect of creative drama method on affective aspect of reading for children. In this context, it is thought that the results of the research will lead educators in terms of developing students' reading motivation and attitudes. The aim of the study conducted with the reference to this is to determine the effect of creative drama method on the reading motivation and attitude of 4 th grade students. Also, it is aimed to determine the ideas of the students related to the implementation progress carried out with creative drama method.

\section{Method}

"One group pretest post test experimental design" was used in the research. In this design, the effect of the experimental process is tested with a study on a single group. The measurements of the subjects relating to the dependent variable are obtained as pre test before the implementation and post test after the implementation using the same subjects and the same measurement instruments (Büyüköztürk et.al, 2013). The collection, analysis and interpretation of the data were all achieved through quantitative research technique. In this context, in the research, the reading motivation and attitude of the students before and after implementation was determined using relevant measurement instruments.

The study group of the research consists of 16 students in 4th grade in a primary school of a town in Trabzon in 2015-2016 school year. 10 of the students participated in the research are girls and 6 of them are boys. The students are between the ages of 8-9. The students don't have any previous experience related to creative drama.

In the research, Motivation to Read Profile (MRP) adapted to Turkish by Yıldız (2013) was used to determine the reading motivations of the students. Also in the research, "Attitude scale towards reading" was used developed by Susar Kırmızı (2008) in order to determine the attitudes of students towards reading.

In the research, the students performed reading studies with creative drama method within the Turkish lesson. The conducted studies were prepared by the drama trainer, Erdoğan (2015). The implementation lasted 30 school hours. 7 different implementations were performed in this period.

\section{Result and Discussion}

The results of the research reveal that the creative drama method effects positively the reading motivation of students. In the creative drama process, students make various activities related to the text or book they will read during the warm up / preparation phase. By these activities they are prepared physically, 
cognitively and emotionally and become eager for the reading process. Then they do animation exercises using different techniques of creative drama about text. According to Adomat (2012), These drama studies help students examine and understand the reading text more deeply. These studies may be done before the reading text, as well as during and after the reading. Reading process integrated with drama enhances students' commitment to reading. This situation has a positive effect on students' sense of self and the importance they give to reading.

In the drama process, students perform unique, entertaining and original activities instead of boring, monotonous activities (Tandy \& Howell, 2010). They look at things from different ways and think deeply about them. In this context, Creative drama supports reading, which is an active meaning extraction process. Because it helps students to develop many different perspectives by pretending and thinking about the text. These different perspectives and opinions also help to establish non-text meaning. In this process, the student who is engaged with the text and the reading material for a longer time changes the point of view to read at the same time (Wilhelm, 2007). In this research, it is thought that the reading studies made by the creative drama method provides the students better understanding of the text and supports the reading process. This situation positively affects the reading motivation of students.

In the process of creative drama, the students make studies about reading skills on the attractive subjects which are suitable for their purposes. When students are faced with reading missions that do not serve their goals and their interests, they quit reading. This prevents them from making readings meaningful and their motivation goes down. In this context, for the reading activities to be carried out in the lesson, the teachers should necessarily have knowledge about the students' interests. A teacher who knows the interests of students choose the reading materials which they will use for the class according to this and can do more fun on this material. The reading activities given according to the students' interests allow them to have fun. This helps students improve their reading and motivation (Merisuo-Storm, 2006; Pitcher et al., 2007). In this research, the studies on reading with the creative drama method have been prepared and implemented for the students.

Another result of the research is that creative drama method does not affect students' attitudes towards reading. According to Schiefele et al. (2012), attitudes toward reading includes values many variables such as internal motivation, beliefs, goals, point of view, ambitiousness, curiosity, loyalty. In this context, attitude is a multidimensional and complex concept. Changing attitudes requires a long process. In the research, it is observed that the students' attitudes towards reading have improved but no meaningful difference has occurred. This can be explained by the fact that the application period is not long enough to develop the attitude toward reading.

In the light of the results obtained in the research, the following suggestions can be made for the reading instruction in the primary school and the subsequent researches:

1. In order to increase the motivation of the students to read in Turkish lessons, creative drama method should be utilized.

2. Longer studies with creative drama should be done to increase students' attitudes towards reading.

3. Similar studies should be conducted at different grade levels and in different study groups.

4. The effect of creative drama method on other language skills and the factors influencing these skills should be investigated. 